DOI: https://doi.org/10.47405/mjssh.v5i3.373

\begin{tabular}{|c|c|}
\hline 4 & Malaysian Journal of Social Sciences and Humanities (MJSSH) \\
\hline $\begin{array}{l}\text { Malaysian Journal of } \\
\text { Social sciences and }\end{array}$ & Volume 5, Issue 3, March 2020 \\
\hline (MJ-SSH) & e-ISSN : 2504-8562 \\
\hline & $\begin{array}{l}\text { Journal home page: } \\
\text { www.msocialsciences.com }\end{array}$ \\
\hline
\end{tabular}

\title{
Kesan Komitmen Organisasi Pendidikan Sebagai Moderator ke atas Hubungan Kepimpinan Teknologi Pengetua dalam Pengurusan Kurikulum dengan Efikasi Kendiri Guru
}

\author{
Roslee Talip ${ }^{1}$, Tisebio Anak Tiop ${ }^{1}$ \\ ${ }^{1}$ Fakulti Psikologi dan Pendidikan, Universiti Malaysia Sabah (UMS) \\ Correspondence: Tisebio Anak Tiop (tisebiotiop570@gmail.com)
}

\begin{abstract}
Abstrak
Kajian ini yang dijalankan adalah mengenai kepimpinan teknologi pengetua dalam pengurusan kurikulum, efikasi kendiri guru dan komitmen organisasi pendidikan. Secara khususnya, kajian ini juga mengenal pasti hubungan kepimpinan teknologi pengetua dalam pengurusan kurikulum dengan efikasi kendiri guru. Seterusnya, kajian ini juga mengenal pasti kesan komitmen organisasi pendidikan sebagai moderator dalam hubungan kepimpinan teknologi pengetua dalam pengurusan kurikulum dengan efikasi kendiri guru. Kajian ini adalah kajian berbentuk kuantitatif dengan menggunakan soal selidik sebagai instrumen dan dianalisis menggunakan perisian SPSS 25.0. Data dikumpul menggunakan satu set borang soal selidik adaptasi yang ditadbir ke atas 306 orang guru. Analisis deskriptif menunjukkan kepimpinan teknologi pengetua dalam pengurusan kurikulum, efikasi kendiri guru dan komitmen organisasi pendidikan diamalkan pada tahap yang tinggi. Ujian korelasi Pearson pula menunjukkan terdapat hubungan linear positif yang sederhana bagi kepimpinan teknologi pengetua dalam pengurusan kurikulum dengan efikasi kendiri guru. Manakala, dengan menggunakan regresi hierarki didapati bahawa pentadbir perlu meningkatkan komitmen organisasi kerana ianya memberi kesan moderator yang positif terhadap hubungan kepimpinan teknologi pengetua dalam pengurusan kurikulum dan efikasi kendiri guru. Implikasi dan cadangan kajian lanjut turut dibincangkan.
\end{abstract}

Kata kunci: kepimpinan teknologi pengetua dalam pengurusan kurikulum, efikasi kendiri guru, komitmen organisasi pendidikan

\section{The Effect of Educational Organizational Commitment as a Moderator Towards Principal Technology Leadership in Curriculum Management ad Teachers' Self- Efficacy}

\begin{abstract}
This study focuses on principal technology leadership in curriculum management, teachers' selfefficacy and educational organizational commitment. To be specified, this research identify the relationship between principal technology leadership in curriculum management and teachers' selfefficacy. This is a quantitative research using questionnaire as an instrument and is analysed using SPSS 25.0. Data was collected through a set of adapted questionnaires administered to 306 teachers. Descriptive analysis principal technology leadership in curriculum management, teachers' self-efficacy and educational organizational commitment being practised at a high level. Pearson correlation test indicated a moderate positive linear relationship for principal technology leadership in curriculum
\end{abstract}


DOI: https://doi.org/10.47405/mjssh.v5i3.373

management with teachers' self-efficacy. Meanwhile, using hierarchical regression is found that administrators need to increase the organizational commitment as it gives the impression of a positive moderator on the relationship between principal technology leadership in curriculum management and teachers' self-efficacy. The implications and suggestions for further study are also discussed.

Keywords: principal techology leadership in curriculum management, teachers' self-efficacy, educational organizational commitment

\section{Pengenalan}

Sistem pendidikan di Malaysia telah mengalami transformasi pendidikan berhadapan dengan dasar Pelan Pembangunan Pendidikan Malaysia (PPPM 2013-2025) yang dilaksanakan secara berfasa meliputi pelbagai dimensi. Anjakan ketujuh dalam (PPPM 2013-2025) bertujuan untuk memanfaatkan Teknologi Maklumat dan Komunikasi (ICT) bagi meningkatkan kualiti pembelajaran. Oleh itu, guru dituntut agar bersiap sedia bagi menerima perubahan teknologi dalam pendidikan. Keupayaan dan kebolehan guru dalam mengaplikasikan dan menggunakan teknologi merupakan satu kewajiban bagi menjadikan proses pengajaran dan pembelajaran yang menarik. Menurut Cocca, Cocca, Martinez dan Bulnes (2018) keyakinan guru merangka dan mengatur strategi pengajaran merupakan titik tolak kepada perubahan inovasi pembelajaran yang berupaya untuk meningkatkan pencapaian pelajar. Justeru, aspek kecekapan kendiri atau efikasi kendiri (Self-Efficacy) perlu ada dalam diri setiap guru bagi meningkatkan kualiti dan keberkesanan sistem pendidikan negara. Efikasi kendiri merujuk secara saintifik kepada sejauh mana individu mempunyai keyakinan terhadap kemampuan dirinya dalam mencapai sesuatu matlamat.

Perubahan dalam sistem pendidikan negara memerlukan kecekapan kendiri yang tinggi daripada guru dan pemimpin sekolah agar dapat memenuhi matlamat pendidikan negara. Walau bagaimanapun, profesion keguruan sentiasa berhadapan dengan banyak halangan dan cabaran dari sudut kebendaan, intelektual, pemikiran, kerohanian, kebudayaan, ideologi baharu dan masalah etika (Hakimi Ismail, 2015). Oleh itu, sebagai golongan yang profesional guru perlu memenuhi pelbagai keperluan kompetensi untuk melaksanakan tugas dan kuasa mereka secara profesional. Bagi menangani cabaran tersebut, tanggungjawab guru amat besar dalam menyediakan serta membentuk insan peribadi mulia berperwatakan unggul dalam membina negara bangsa yang berkualiti (Khair, 2015).

Pada masa kini, kepimpinan teknologi dianggap sebagai faktor penting yang mempengaruhi kejayaan integrasi teknologi di sekolah (Metcalf, 2012). Kepimpinan teknologi menjadi salah satu faktor penting dalam memahami kejayaan perubahan sesebuah organisasi (Mei Kin et al., 2018). Kini, pemimpin perlu lebih peka dan bersedia menerima perubahan yang mendadak melalui penerapan ICT dalam organisasi (Espin, Stewart dan Thurston (2018). Kepimpinan teknologi merupakan keperluan yang penting kepada pengurusan yang lebih cekap dalam bidang ICT. Walaupun pelbagai gaya kepimpinan sebelum ini sudah wujud, namun tidak ada satu pun yang menyumbang kepada pentadbiran organisasi berlandaskan ICT secara menyeluruh. Seseorang pemimpin teknologi mampu untuk memberikan semangat dan motivasi kepada pekerja melalui kemudahan teknologi semasa (Akcil et al., 2017). Oleh itu, kecemerlangan sesebuah institusi pendidikan adalah bergantung kepada pemimpinnya (Mansor dan Hamzah, 2015).

Komitmen organisasi adalah antara penyelidikan yang dijalankan dengan baik dalam penyelidikan organisasi (Ahmad, Ather dan Hussain, 2014). Dalam konteks sesebuah organisasi, Mareena et al. (2011) menyatakan bahawa komitmen dari pekerja untuk organisasi amatlah diperlukan agar matlamat organisasi dapat dicapai. Individu yang mempunyai komitmen yang tinggi terhadap matlamat yakin bahawa matlamat tersebut adalah penting dan boleh dicapai, mengekalkan keahlian dan merupakan aset yang sangat bernilai dalam organisasi (Abdulkareem et al., 2015).

Dalam bidang pendidikan, komitmen merupakan unsur-unsur psikologi guru yang mempunyai kaitan dengan profesion keguruan. Menurut Saimah (2013), tingkah laku guru yang mempunyai satu 
DOI: https://doi.org/10.47405/mjssh.v5i3.373

kepercayaan yang kuat terhadap nilai dan matlamat, bersemangat sukarela untuk berusaha meningkatkan pencapaian organisasi dan keinginan untuk terus kekal di dalam organisasi sekolah. Komitmen organisasi merujuk kepada situasi kerja dan rasa tanggungjawab individu bagi meningkatkan prestasi organisasi (Rabindarang et al., 2014). Apabila guru komited terhadap organisasi pendidikan, guru dapat melaksanakan tugas mereka dengan lebih cekap kerana ianya membawa satu kepuasan dalam diri.

\section{Pernyataan Masalah}

Efikasi kendiri guru merupakan komponen penting dalam bidang pendidikan kerana implikasinya terhadap kejayaan proses pengajaran dan pembelajaran di samping turut membantu dalam meningkatkan kualiti pendidikan negara. Menurut Bandura (1986), efikasi kendiri mempengaruhi prestasi dengan meningkatkan usaha dan kecekalan. Keupayaan guru menggunakan ICT sangat dituntut bagi menggarap strategi pengajaran yang mempesona di samping menarik minat pelajar menyertai setiap aktiviti pembelajaran (Cansoy dan Parlar 2018). Walau bagaimanapun, terdapat golongan guru yang kurang peka dengan perkembangan ICT semasa bagi diketengahkan sebagai bahan bantu mengajar dalam bilik darjah (Alt, 2018). Sungguhpun tersedia peralatan ICT di sekolah, namun guru masih kurang cekap untuk memanfaatkan peluang tersebut (Joo et al., 2018). Antara isu yang sering dibangkitkan ialah kegagalan guru melaksanakan pembelajaran dan pemudahcaraan (PdPc) berkualiti, ketiadaan infrastruktur asas yang lengkap, masalah kekurangan guru berkelayakan, sumber bahan pengajaran yang terhad dan yang paling ketara adalah disebabkan perubahan kurikulum yang drastik (Utusan Borneo Sabah, 2017). Petanda ini menunjukkan tahap efikasi kendiri guru dalam menggunakan ICT masih lagi pada tahap yang membimbangkan (Hatlevik dan Hatlevik, 2018).

Kepimpinan pengetua yang berkesan sering dikaitkan dengan tingkah laku pemimpin, yang menggambarkan bagaimana pemimpin bertindak, berinteraksi, mengawal emosi dan berkomunikasi dengan kakitangan dalam organisasi (Yukl, 2013). Implikasinya, guru akan berasa selesa dengan persekitaran kerjanya, merasakan mereka sentiasa disokong oleh pihak pentadbir dan beranggapan bahawa pengetua mampu mengunakan pengaruh pentadbirannya untuk kebaikan guru serta dapat meningkatkan tahap efikasi kendiri guru (Khairiah, 2013). Dalam erti yang mudah, pengetua diamanahkan sebagai penggerak utama kepada peningkatan efikasi kendiri guru dalam setiap yang dilaksanakan (Sun dan Xia, 2018). Walau bagaimanapun, masalah kepimpinan pengetua semakin meningkat dan bertambah kompleks dewasa ini (Ibukun, Oyewole, dan Abe, 2011). Menurut Toprak dan Summak (2014), masalah kepimpinan dan kekurangan penglibatan pengetua dalam inisiatif perubahan turut dikesan dalam literatur sebagai punca meruntunnya komitmen guru.

Kajian-kajian lampau turut menunjukkan bahawa ramai pemimpin sekolah mempunyai tahap dan kemahiran teknologi ICT yang rendah (Sathiamoorthy, 2013). Selain itu, masih terdapat pengetua yang kurang memahami fungsi kepimpinan teknologi bagi menggalakkan guru mengintegrasikan ICT dengan berkesan (Alkrdem, 2014). Pengetahuan dan kemahiran penggunaan ICT pengetua juga masih kurang mencapai standard sepertimana yang dicadangkan oleh NET-A (Ozkan et al., 2017). Pelbagai mandat telah diberikan kepada pengetua, namun mereka masih buntu untuk menterjemahkan peranan kepimpinan yang sebenar (Banoglu et al., 2016; Wong dan Khadijah Daud, 2017). Fenomena ini jelas menggambarkan bahawa tahap kepimpinan teknologi pengetua masih lagi berada pada prestasi yang rendah dan kurang memuaskan (Ugur dan Koc, 2019).

Komitmen organisasi turut menjadi faktor penting dalam menentukan kejayaan organisasi (Razak, Darmawan dan Keeves, 2010; Yukl, 2010; Fuziah dan Mohd Izham, 2011; Mohamed Sani, Ghavifekr, Ling, Siraj, dan Azeez, 2014) kerana ia meningkatkan kreativiti (Carlos dan Filipe, 2011) dan mengurangkan niat mereka untuk meninggalkan organisasi pendidikan untuk mencapai visi dan matlamat sekolah serta mereka akan lebih cenderung untuk mempunyai motivasi dan komitmen yang tinggi terhadap sekolah. Namun begitu, menurut Madiha (2012) "komitmen organisasi telah diberi sedikit perhatian dalam penyelidikan pendidikan" (ms 133). Peranan komitmen organisasi pendidikan sebagai penyederhana turut memperoleh hubungan yang tidak konsisten. Terdapat kajian-kajian terdahulu telah menjadikan komitmen organisasi sebagai penyederhana pelbagai variabel seperti kajian 
DOI: https://doi.org/10.47405/mjssh.v5i3.373

Butali dan Njoroge (2017) dan Sabwami (2015). Walau bagaimanapun, belum terdapat kajian yang benar-benar menjadikan variabel komitmen organisasi pendidikan sebagai penyederhana bagi hubungan kepimpinan teknologi pengetua dalam pengurusan kurikulum dengan efikasi kendiri guru.

\section{Objektif Kajian}

Kajian ini dijalankan atas beberapa objektif tertentu seperti berikut:

i. Mengenal pasti tahap kepimpinan teknologi pengetua dalam pengurusan kurikulum, efikasi kendiri guru dan komitmen organisasi pendidikan.

ii. Mengenal pasti hubungan kepimpinan teknologi pengetua dalam pengurusan kurikulum dengan efikasi kendiri guru.

iii. Mengenal pasti kesan komitmen organisasi pendidikan sebagai moderator dalam hubungan antara kepimpinan teknologi pengetua dalam pengurusan kurikulum dan efikasi kendiri guru.

\section{Hipotesis Kajian}

Berpandukan objektif kajian, dua hipotesis nul telah dibina. Kajian ini menggunakan aras hipotesis nul berikut:

$\mathrm{Ho}^{1}$ Tidak terdapat hubungan yang signifikan tahap kepimpinan teknologi pengetua dalam pengurusan kurikulum dengan efikasi kendiri guru

$\mathrm{Ho}^{2}$ Kesan komitmen organisasi pendidikan bukan sebagai moderator dalam hubungan antara kepimpinan teknologi pengetua dalam pengurusan kurikulum dan efikasi kendiri guru.

\section{Tinjauan Literatur}

\section{Efikasi Kendiri Guru}

Efikasi kendiri diri guru dapat dilihat dari dua aspek: keberkesanan pengajaran peribadi (KPP) dan kecekapan pengajaran umum (KPU). KPP dianggap sebagai kepercayaan guru dalam kebolehan dan kemahiran yang menyebabkan pelajar berubah. KPU dianggap sebagai kepercayaan bahawa guru mempunyai keupayaan terhad dan terhad untuk mengubah pelajar kerana faktor persekitaran, latar belakang dan ibu bapa. Di samping itu, efikasi kendiri guru adalah kepercayaan terbina dalam keupayaan guru untuk mempengaruhi pelajar untuk belajar dan mencapai pencapaian cemerlang termasuk pelajar yang kurang bermotivasi dan bermasalah (Gibson dan Dembo, 1984). Terdapat tiga faktor yang dikemukakan oleh Tschannen-Moran dan Hoy (2001) bagi mewakili efikasi kendiri guru iaitu efikasi terhadap strategi pengajaran, efikasi terhadap pengurusan bilik darjah dan akhirnya efikasi terhadap penglibatan pelajar. Tschannen-Moran dan Hoy (2001) mendefinisikan efikasi kendiri guru sebagai keyakinan guru terhadap keupayaan mereka untuk mengajar dan memotivasi pelajar tanpa mengira kebolehan dan latar belakang pelajar.

Albert Bandura (1997) merupakan antara pelopor dalam kajian berkaitan efikasi kendiri. Bandura (1986) menyatakan efikasi mempengaruhi prestasi dengan meningkatkan usaha dan kecekalan seseorang. Tahap efikasi yang tinggi memberikan kesan atau impak kepada pergerakan tingkah laku, usaha dan ketahanan diri yang tinggi bagi menghadapi sebarang halangan. Efikasi diri merupakan outcome dari proses pertimbangan, integrasi dan penilaian maklumat mengenai kebolehan seseorang individu. Hal ini membolehkan individu tersebut membuat keputusan atau pilihan atas setiap usaha yang dilakukan dalam melaksanakan tugas. Di dalam kajian yang dijalankan oleh Awanis et al. (2016) dan Horton (2013) berjaya membuktikan efikasi kendiri guru adalah pengerak utama kepada kejayaan pelajar. Walau bagaimanapun, efikasi kendiri guru ini adalah luas bentuknya yang mengabungkan kepercayaan guru secara umum dan kepercayaan kebolehan individu. Efikasi kendiri guru merujuk 
kepada Tschannen-Moran, Hoy dan Hoy (1998) adalah kepercayaan guru tentang keupayaan diri bagi menyusun atur dan melakukan satu siri tindakan yang diperlukan untuk menyempurnakan tugasan pengajaran dalam konteks yang spesifik selain mempunyai tingkah laku serta sikap yang positif terhadap setiap usaha mereka. Dengan kata lain, efikasi kendiri guru boleh diterjemahkan sebagai kepercayaan guru terhadap keupayaan mereka untuk mengajar dalam situasi pengajaran. Berpandukan literatur yang telah djelaskan, efikasi kendiri guru dalam kajian ini dioperasikan dari tiga konstruk utama iaitu, strategi pengajaran, pengurusan bilik darjah dan penglibatan murid.

Kajian lepas menunjukkan tahap efikasi kendiri guru memperoleh dapatan yang berbeza merentasi kawasan dan tahun penyelidikan. Beberapa kajian menunjukkan tahap efikasi kendiri guru sama ada melibatkan strategi pengajaran, pengurusan bilik darjah mahupun penglibatan murid berada pada aras tinggi. Di dalam konteks Malaysia, Shafinaz (2017) adalah antara kajian yang mendapati efikasi kendiri guru berada pada tahap yang tinggi dalam kajian yang dibuat. Seterusnya, kajian yang dijalankan oleh Nurulakhma Yahya, Harun Baharudin dan Mohd Isa Hamzah (2017) juga mendapati bahawa tahap efikasi kendiri guru berada pada tahap yang tinggi dalam pengajaran bahasa Arab. Hasil dapatan kajian mereka ini menunjukkan bahawa efikasi kendiri guru dalam aspek strategi pengajaran, pengurusan bilik darjah dan penglibatan murid dalam pengajaran dan pembelajaran berada di tahap tinggi. Seterusnya, kajian oleh Azizuddin, Fleva dan Qazi (2015) terhadap 200 orang guru mendapati tahap efikasi guru sekolah di India adalah pada tahap tinggi. Guru yang mempunyai tahap efikasi kendiri yang tinggi menunjukkan prestasi yang cemerlang dalam efikasi pengajaran mereka dan mempunyai harga diri yang tinggi. Selain itu, kajian oleh Linda Hoxha dan Zamira Hyseni-Duraku (2017), berkaitan "Hubungan antara kepimpinan pendidikan dan efikasi kendiri guru" juga menunjukkan tahap efikasi kendiri guru adalah tinggi. Hasil kajian ini juga mendapati bahawa tanggapan individu dan rangsangan intelektual merupakan peramal yang kuat terhadap efikasi kendiri guru dalam pengajaran.

\section{Kepimpinan Teknologi Pengetua Dalam Pengurusan Kurikulum}

Kepimpinan teknologi merujuk kepada keupayaan dan daya pengaruh pemimpin membangunkan potensi dan kapasiti ahli organisasi iaitu guru dan pelajar seiring dengan perubahan melalui penghasilan inovasi yang dapat membangunkan kecemerlangan dan keberkesanan sekolah (Moktar 2011). Kepimpinan teknologi adalah kombinasi strategi dan teknik yang umum kepada kepimpinan tetapi memerlukan perhatian yang khusus terhadap teknologi, khususnya yang berkaitan dengan akses kepada peralatan, kemaskini teknologi dan menyedari bahawa perkembangan profesional serta pengintegrasian teknologi adalah sentiasa berubah mengikut perkembangan waktu dan zaman.

Pengetua sebagai pengurus sekolah perlu mendasari perkembangan kurikulum bagi memenuhi keperluan pelajar dan mendalami perkembangan kemahiran pengurusan agar kurikulum dapat disampaikan secara cekap dan berkesan walaupun ada kekangan sumber yang terhad. Selain itu, pengetua juga bertindak sebagai pemimpin kurikulum di sekolah dan perlu memahami bahawa fungsi ICT di sekolah bukan hanya untuk mempromosi kearifan komputer, ianya adalah disebabkan teknologi dianggap sebagai 'gelombang masa depan'. Fungsi teknologi di sekolah adalah untuk mempertingkatkan pengajaran dan pembelajaran sejajar dengan kurikulum dan penilaian (Hong dan Koh, 2002). Oleh itu, pengetua-pengetua perlu menilai teknologi pendidikan sebagai satu penyelesaian masalah-masalah pengajaran. Pengetua sebagai pemimpin teknologi berupaya menyuntik motivasi guru melalui kemudahan teknologi semasa (Akcil et al., 2017).

Berdasarkan penjelasan yang telah dibincangkan, kepimpinan teknologi pengetua dalam kajian ini didefinisikan sebagai keupayaan dan daya pengaruh pengetua dalam membangunkan potensi guru dan pelajar seiring dengan perubahan melalui penghasilan inovasi yang dapat membangunkan kecemerlangan dan keberkesanan sekolah. Kepimpinan teknologi pengetua dalam kajian ini diukur dari sudut persepsi guru merangkumi beberapa konstruk tingkah laku pengetua yang ditunjukkan iaitu kepimpinan berwawasan, budaya pembelajaran era digital, kecemerlangan amalan profesional, penambahbaikan menyeluruh dan warga digital. 
Dapatan kajian oleh Raamani Thannimalai dan Arumugam Raman (2018) dalam kalangan pengetua dan guru di 90 buah sekolah menengah di Negeri Kedah menunjukkan bahawa tahap amalan kepimpinan teknologi pengetua adalah tinggi. Dimensi peningkatan menyeluruh adalah merupakan yang paling tinggi dalam kelima-lima dimensi yang diamalkan oleh pengetua. Persamaan hasil dapatan berkaitan tahap amalan kepimpinan teknologi pengetua juga dilaporkan dalam kajian Noraini Abdullah, Hamidon Khalid dan Mohd Izham Mohd Hamzah. (2015). Mereka berpendapat bahawa pemimpin sekolah abad ke-21 mempunyai peranan penting dalam pengintegrasian teknologi sama ada dalam pengajaran dan pembelajaran mahupun dalam pengurusan dan kepimpinan. Selain itu, semua guru mesti berganding bahu untuk mempertingkatkan lagi penggunaan ICT dalam proses pembelajaran dan pengajaran serta amalan profesional seharian. Menyentuh perkara yang sama, Fisher dan Waller (2013) dalam penyelidikannya turut mendapati kepimpinan teknologi diamalkan pada tahap tinggi. Kajian oleh Alkrdem (2014) juga menunjukkan bahawa amalan kepimpinan teknologi pengetua adalah tinggi. Dapatan yang sama juga diiperolehi dalam kajian Alenezi (2017) yang mendapati bahawa pengetua mengamalkan amalan kepimpinan teknologi pada tahap yang tinggi.

\section{Komitmen Organisasi Pendidikan Sebagai Moderator dalam Hubungan Kepimpinan Teknologi Pengetua Dalam Pengurusan Kurikulum dan Efikasi Kendiri Guru}

Variabel penyederhana mempengaruhi sifat hubungan antara dua pemboleh ubah lain, tanpa perlu dikaitkan dengan salah satu daripada mereka. (Blum dan Naylor, 1968; Zedeck, 1971; Korman, 1974; Terborg, 1980). Kepentingan mengkaji kesan penyederhana memang diiktiraf dalam literatur kajian. (Connor-Smith dan Compas, 2002; Littleton, Horsley, John dan Nelson, 2007). Penjelasan terhadap keputusan yang tidak sesuai boleh berlaku sekiranya penyelidik gagal mempertimbangkan kemungkinan kesan penyederhana dalam data (Dardas dan Ahmad, 2015). Berdasarkan beberapa teori dan model yang telah dikemukakan, variabel komitmen organisasi pendidikan merupakan konstruk yang memberi pengaruh dan mampu menjelaskan perubahan dalam variabel bersandar sesuatu kajian. Kajian yang menjadikan komitmen organisasi pendidikan sebagai variabel penyederhana telah dilakukan ramai penyelidik sama ada dalam pelbagai bidang termasuk pendidikan. Walaupun variabel yang dikaji tidak menyamai dengan kajian ini, namun penggunaan variabel penyederhana komitmen organisasi dalam kajian tersebut dapat membuktikan bahawa konstruk ini mempunyai peranan dalam menjelaskan hubungan antara variabel bersandar dan variabel bebas kajian.

Komitmen organisasi dikaitkan dengan tahap kepercayaan dan penerimaan seseorang terhadap tujuan organisasi serta melakukan pelbagai usaha untuk kepentingan organisasi (Angle dan Perry, 1981). Hal ini dapat digambarkan apabila seseorang yang mempunyai komitmen yang tinggi akan menggunakan berusaha dengan pelbagai cara demi untuk mencapai matlamat dan tujuan organisasi. Manakala, sebaliknya pula bagi yang mempunyai komitmen yang rendah, seseorang itu akan berusaha dengan pelbagai cara demi untuk kepentingan dirinya sendiri. Dalam kajian yang dilakukan oleh Butali dan Njoroge (2017), menunjukkan bahawa komitmen organisasi sebagai penyederhana yang mempengaruhi hubungan antara pembangunan dalam latihan dan prestasi terhadap organisasi. Hal ini boleh dikaitkan dengan komitmen organisasi memberikan pengaruh yang tinggi terhadap keberkesanan organisasi. Mathew dan Zacharias (2016), menyatakan komitmen dan dedikasi pekerja terhadap matlamat organisasi dipengaruhi oleh komitmen organisasi sebagai penyederhana.

Kajian yang dilakukan Sabwami Butali (2015) adalah antara penyelidikan yang dirujuk bagi melihat kesan komitmen organisasi sebagai penyederhana. Dapatan analisis menunjukkan bahawa komitmen organisasi adalah sebagai penyederhana hubungan antara amalan prestasi tinggi di tempat kerja dengan prestasi organisasi. Dalam kajian semasa, penemuan menunjukkan bahawa komitmen organisasi boleh digunakan sebagai pemboleh ubah untuk meningkatkan keberkesanan organisasi sekolah. Penekanan ini disokong oleh penyelidikan terdahulu (Ali et al., 2016) yang mendapati bahawa komitmen organisasi memainkan peranan penting dalam membentuk iklim sekolah yang efektif. Sementara itu, (Ali et al., 2016) mempercayai bahawa kepimpinan akademik oleh pengetua dapat meningkatkan komitmen guru terhadap organisasi, keberkesanan pengajaran guru dan sumbangan terhadap pembangunan dan keberkesanan sekolah. Berdasarkan hasil dapatan kajian ini mendapati bahawa komitmen organisasi terbukti menjadi penyederhana hubungan identiti organisasi dan penilaian positif hasil perubahan. Walaupun kebanyakan variabel peramal dan kriteria dalam kajian-kajian yang ditemui 
DOI: https://doi.org/10.47405/mjssh.v5i3.373

tidak menyamai variabel dalam kajian ini, namun fokus kepada peranan penyederhana komitmen organisasi adalah cukup jelas memberikan kesan terhadap hubungan kedua-dua variabel kajian.

\section{Kerangka Konseptual Kajian}

Dalam kajian ini, efikasi kendiri guru ditetapkan sebagai pemboleh ubah bersandar, kepimpinan teknologi pengetua dalam pengurusan kurikulum sebagai pemboleh ubah bebas kajian, manakala komitmen organisasi pendidikan bertindak sebagai pemboleh ubah moderator. Rajah 1 menunjukkan kerangka konseptual mengenai hubungan antara pemboleh ubah dalam kajian ini.

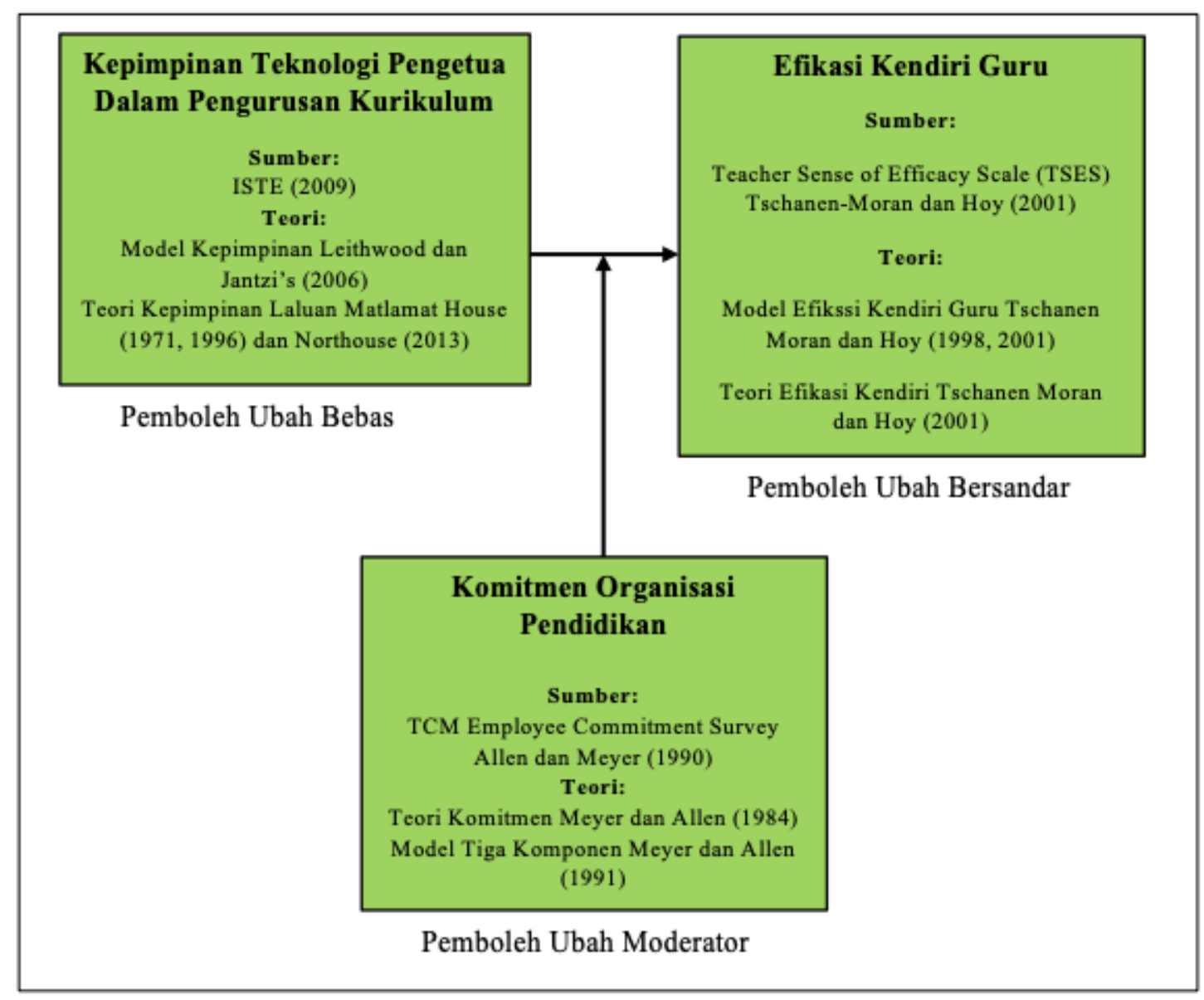

Rajah 1: Kerangka Konseptual Kajian

\section{Metod Kajian}

Reka bentuk kajian ini adalah jenis bukan eksperimental. Kajian ini menggunakan kaedah tinjauan sampel, yang bertujuan mengumpul maklumat daripada sebahagian populasi berkaitan pemboleh ubah kajian. Kajian ini menggunakan pendekatan kuantitatif yang melibatkan analisis statistik deskriptif dan inferensi. Populasi dalam kajian ini ditetapkan hanya dalam kalangan guru-guru sekolah menengah harian biasa yang menerima bantuan penuh kerajaan sahaja. Bersumberkan data yang diperoleh daripada Jabatan Pendidikan Negeri Sabah (2019), terdapat 1,492 orang guru sedang berkhidmat di 18 buah sekolah menengah harian biasa di daerah Kota Kinabalu, Sabah. Berdasarkan prinsip-prinsip asas statistik yang perlu dipatuhi untuk analisis data, penyelidik menetapkan saiz sampel kajian sebanyak 306 orang berpandukan pada saranan Krejcie dan Morgan (1970). Borang soal selidik merupakan instrumen utama dalam kajian ini. 
DOI: https://doi.org/10.47405/mjssh.v5i3.373

Penggunaan borang soal selidik adalah sesuai digunakan untuk mendapatkan data terutamanya kajian berbentuk kuantitatif yang memerlukan saiz sampel besar dan menyeluruh (Jacob dan Ary, 1990; Babbie, 2001; Mohd. Majid Konting, 2000; Chua, 2006). Skala pengukuran yang digunakan dalam kajian ini ialah skala Likert lima mata. Alat kajian yang digunakan untuk mengukur pemboleh ubah bebas kajian ini ialah Principal Technology Leadership Assessment (PTLA) yang telah dibangunkan International Society for Technology In Education (ISTE) (2009). Beberapa penyelidik terdahulu seperti Leong (2017), Hamzah M. et al. (2016), Faridah Juraime \& Mohd Izham Mohd Hamzah, (2017) dan terkini Raamani Thannimalai dan Arumugam Raman (2018) dan Norhayati Md Darus (2018) telah menggunakan alat pengukur ini.

Pemboleh ubah bersandar kajian pula diukur menggunakan Teacher Sense of Efficacy Scale (TSES) oleh Tschanen-Moran dan Hoy (2001). Instrumen ini sangat bersesuaian dan bertepatan sebagai pengukuran variabel efikasi kendiri guru dari aspek strrategi pengajaran, pengurusan bilik darjah dan penglibatan murid. Beberapa kajian lepas telah menggunakan soal selidik ini seperti Nurulakhma Yahya, Harun Baharudin dan Mohd Isa Hamzah (2017), Shafinaz A. Maulod, Chua Yan Piaw, Hussein Ahmad dan Leong Mei Wei (2017), dan Noor Zailani binti Khozan dan Azlin Norhaini binti Mansor (2017).

Seterusnya, alat kajian yang digunakan untuk mengukur pemboleh ubah moderator komitmen organisasi pendidikan ialah TCM Employee Commitment Survey oleh Allen and Meyer (1990). Kebolehpercayaan enam konstruk dalam soal selidik ini adalah antara 0.55 hingga 0.95 . Beberapa penyelidik telah menggunakan instrumen ini seperti Siva, Khuan dan Khoo (2018), Jeyasushma (2017) dan Fatimah (2014). Kajian ini menggunakan soal selidik yang diadaptasi dan diterjemahkan oleh Jeyasushma (2017) dari TCM Employee Commitment Survey oleh Allen dan Meyer (1990) yang digunakan untuk mengkaji tahap komitmen guru. Rasional pemilihan ini dilakukan adalah atas kesesuaian dalam konteks pendidikan di Malaysia.

\section{Dapatan Kajian}

\section{Tahap Kepimpinan Teknologi Pengetua Dalam Pengurusan Kurikulum, Efikasi Kendiri Guru dan Komitmen Organisasi Pendidikan}

Analisis deskriptif iaitu kekerapan, peratusan, dan min digunakan untuk menentukan kepimpinan teknologi pengetua dalam pengurusan kurikulum, efikasi kendiri guru dan komitmen organisasi Pendidikan. Tahap pemeringkatan adalah berdasarkan panduan yang diberikan oleh Levin dan Rubin (1998) dan Mohd Yusof (2006). Tahap pemeringkatan dilaporkan sama ada tinggi, sederhana, atau rendah ditunjukkan dalam Jadual 2.

Jadual 2: Tafsiran Skor Min

\begin{tabular}{cc}
\hline Purata Min & Pengelasan Tahap \\
\hline $1.00-2.33$ & Rendah \\
$2.34-3.67$ & Sederhana \\
$3.68-5.00$ & Tinggi \\
\hline
\end{tabular}

Keputusan analisis pemeringkatan tahap ditunjukkan dalam Jadual 3. Hasil analisis menunjukkan ketiga-tiga pemboleh ubah diamalkan pada tahap tinggi. Pemboleh ubah yang mempunyai skor tertinggi adalah efikasi kendiri guru $(\mathrm{M}=4.22, \mathrm{SD}=0.39)$, diikuti pemboleh ubah kepimpinan teknologi pengetua dalam pengurusan kurikulum $(\mathrm{M}=4.13, \mathrm{SD}=0.43)$, dan pemboleh ubah terendah ialah komitmen organisasi pendidikan $(\mathrm{M}=3.76, \mathrm{SD}=0.54)$. 
DOI: https://doi.org/10.47405/mjssh.v5i3.373

Jadual 3: Tahap Kepimpinan Teknologi Pengetua Dalam Pengurusan Kurikulum dan Efikasi Kendiri Guru

\begin{tabular}{lccc}
\hline \multicolumn{1}{c}{ Pemboleh Ubah } & Skor Min & Sisihan Piawai & Tahap \\
\hline $\begin{array}{l}\text { Kepimpinan } \\
\text { Teknologi Pengetua } \\
\begin{array}{l}\text { Dalam Pengurusan } \\
\text { Kurikulum }\end{array}\end{array}$ & 4.13 & 0.43 & Tinggi \\
$\begin{array}{l}\text { Efikasi Kendiri Guru } \\
\text { Komitmen Organisasi }\end{array}$ & 4.22 & 0.39 & Tinggi \\
Pendidikan & 3.76 & 0.54 & Tinggi \\
\hline Jumlah Keseluruhan & 4.04 & 0.45 & Tinggi \\
\hline
\end{tabular}

\section{Ho $^{1}$ Tidak Terdapat Hubungan Yang Signifikan Kepimpinan Teknologi Pengetua Dalam Pengurusan Kurikulum Dengan Efikasi kendiri Guru}

Keputusan nilai koefisien ujian Korelasi Pearson bagi jumlah sampel kajian $(N=306)$ seperti uang ditunjukkan dalam Jadual 3 menunjukkan terdapat korelasi positif yang signifikan antara pemboleh ubah bebas kepimpinan teknologi pengetua dalam pengurusan kurikulum $(r=0.415, p<0.01)$ dengan pemboleh ubah bersandar efikasi kendiri guru. Kekuatan hubungan adalah sederhana berpandukan indeks korelasi yang dicadangkan Cohen, Manion, dan Morrison (2007). Memandangkan dapatan menunjukkan terdapat hubungan signifikan antara kedua-dua pemboleh ubah, maka Hipotesis Nul 3 $\left(\mathrm{Ho}^{1}\right)$ ditolak. Justeru, kajian menunjukkan bahawa terdapat hubungan kepimpinan teknologi pengetua dalam pengurusan kurikulum dengan efikasi kendiri guru.

Jadual 3: Analisis Ujian Korelasi Pearson di Antara Kepimpinan Teknologi Pengetua Dalam Pengurusan Kurikulum Dengan Efikasi kendiri Guru

\begin{tabular}{ccc}
\hline Pemboleh Ubah & & KTPDPK \\
\hline Efikasi Kendiri Guru & Korelasi Pearson $p($ sig $)$ & $.415^{* *}$ \\
& & .000 \\
\hline
\end{tabular}

*Signifikan pada tahap $p<0.01$ (2-Hujung)

*KTPDPK - Kepimpinan Teknologi Pengetua Dalam Pengurusan Kurikulum

\section{Ho $^{2}$ Kesan Komitmen Organisasi Pendidikan Bukan Sebagai Moderator Dalam Hubungan Antara Kepimpinan Teknologi Pengetua Dalam Pengurusan Kurikulum Dan Efikasi Kendiri Guru}

Hipotesis $\mathrm{Nul} 2\left(\mathrm{Ho}^{2}\right)$ telah dianalisis menggunakan regresi hierarki bagi mengenal pasti kesan komitmen organisasi pendidikan sebagai moderator dalam hubungan antara kepimpinan teknologi pengetua dalam pengurusan kurikulum dan efikasi kendiri guru. Jadual 4 menunjukkan komitmen organisasi pendidikan memberi kesan kepada hubungan kepimpinan teknologi pengetua dalam pengurusan kurikulum.

Jadual 4: Ujian Pengaruh Komitmen Organisasi Pendidikan Sebagai Moderator Kepada Hubungan Kepimpinan Teknologi Pengetua Dalam Pengurusan Kurikulum Dengan Efikasi Kendiri Guru

\begin{tabular}{llccc}
\hline \multicolumn{1}{c}{ Variabel } & $\begin{array}{c}\text { Std Beta } \\
\text { Model 1 }\end{array}$ & $\begin{array}{c}\text { Std Beta } \\
\text { Model 2 }\end{array}$ & $\begin{array}{c}\text { Std Beta } \\
\text { Model 3 }\end{array}$ \\
\hline $\begin{array}{l}\text { Variabel Bebas } \\
\text { Kepimpinan Teknologi }\end{array}$ & Pengetua & .415 & .386 & .809
\end{tabular}


Dalam Pengurusan Kurikulum

\begin{tabular}{lccc}
\hline $\begin{array}{l}\text { Variabel Moderator } \\
\text { Komitmen Organisasi Pendidikan }\end{array}$ & - & .192 & .647 \\
\hline $\begin{array}{l}\text { Interaction Terms } \\
\text { Kepimpinan Teknologi Pengetua }\end{array}$ & & & \\
$\begin{array}{l}\text { Dalam Pengurusan Kurikulum X } \\
\text { Komitmen Organisasi Pendidikan }\end{array}$ & - & - & $-.123^{* *}$ \\
\hline $\mathrm{R}^{2}$ & .172 & .208 & .214 \\
$\mathrm{R}^{2}$ Terlaras & .169 & .203 & .211 \\
Perubahan Dalam R & & .036 & .006 \\
Perubahan Signifikan F & .172 & .000 & .130 \\
\hline
\end{tabular}

Berdasarkan Jadual 4, variabel kepimpinan teknologi pengetua dalam pengurusan kurikulum dimasukkan ke dalam persamaan, nilai $R^{2}$ adalah 0.172 yang menerangkan $17.2 \%$ variasi berlaku terhadap efikasi kendiri guru. Seterusnya, variabel komitmen organisasi pendidikan dimasukkan ke dalam persamaan, jumlah variasi yang menerangkan efikasi kendiri guru meningkat kepada $20.8 \%$ (sig $F=0.00$ ), nilai $\beta=1.92, p<0.01$ menunjukkan komitmen organisasi pendidikan mempunyai pengaruh yang signifikan ke atas efikasi kendiri guru. Ini membuktikan bahawa komitmen organisasi pendidikan ialah peramal yang boleh meningkatkan efikasi kendiri guru. variabel kepimpinan teknologi pengetua dalam pengurusan kurikulum dengan komitmen organisasi pendidikan telah dimasukkan ke dalam persamaan. Nilai $R^{2}=0.214$ menunjukkan bahawa interaksi ini dapat menerangkan variasi efikasi kendiri guru $21.4 \%$. Nilai $\beta=-0.123, p=0.130$ menunjukkan bahawa wujudnya kesan interaksi komitmen organisasi pendidikan terhadap hubungan kepimpinan teknologi pengetua dalam pengurusan kurikulum dengan efikasi kendiri guru namun tidak signifikan pada aras $0.05 \%$. Kesimpulannya, hasil analisis ini memberikan bacaan nilai beta yang tidak signifikan untuk interaksi antara kepimpinan teknologi pengetua dalam pengurusan kurikulum dengan komitmen organisasi pendidikan (Model 3). Manakala untuk Model 1 dan Model 2, ia adalah signifikan. Oleh itu, Hiptesis Nul $2\left(\mathrm{Ho}^{2}\right)$ adalah ditolak. Maka, ini menunjukkan bahawa komitmen organisasi pendidikan telah bertindak sebagai penyederhana terhadap hubungan antara kepimpinan teknologi pengetua dalam pengurusan kurikulum dengan efikasi kendiri guru

\section{Perbincangan Dapatan Kajian}

Berdasarkan analisis deskriptif yang dilakukan, kepimpinan teknologi pengetua dalam pengurusan kurikulum berdasarkan persepsi guru adalah berada pada tahap yang tinggi. Anjakan kelima dalam Pelan Pembangunan Pendidikan Malaysia 2013-2025 adalah bertujuan untuk memastikan kepimpinan prestasi tinggi ditempatkan di setiap sekolah (Kementerian Pendidikan Malaysia, 2013). Sistem pendidikan negara akan menjadi lebih berkualiti dan boleh dipertingkatkan dengan kehadiran pentadbir berprestasi tinggi.

Dapatan kajian ini menyokong kajian Raamani Thannimalai dan Arumugam Raman (2018) sebelum ini yang menunjukkan tahap kepimpinan teknologi pengetua dalam pengurusan kurikulum adalah tinggi. Kajian ini juga selari dengan kajian Noraini Abdullah, Hamidon Khalid dan Mohd Izham (2015) yang mendapati bahawa pemimpin sekolah abad ke-21 mempunyai tugas yang penting dalam pengintegrasian teknologi sama ada dalam pengajaran dan pembelajaran mahupun dalam pengurusan dan kepimpinan. Kajian ini juga menyamai kajian Faridah Juraime dan Mohd Izham (2017) mengenai kepimpinan teknologi pengetua terhadap prestasi akademik sekolah di mana menunjukkan bahawa tahap kepimpinan teknologi pengetua adalah pada tahap tinggi diamalkan. Melalui dapatan kajian ini, terbukti kepimpinan teknologi pengetua dalam pengurusan kurikulum adalah tinggi. Hal ini kerana pengetua memainkan peranan yang penting dalam merancang dan menyokong segala aktiviti-aktiviti akademik dalam usaha untuk mencapai keberkesanan sekolah selaras dengan perkembangan pendidikan semasa yang memberikan penekanan terhadap integrasi teknologi di sekolah. 
Kajian ini juga menyimpulkan efikasi kendiri guru adalah pada tahap yang tinggi. Perkara ini bermakna guru mempunyai kepercayaan yang tinggi dalam pengajarannya. Dapatan kajian ini disokong oleh kajian Shafinaz (2017) yang menunjukkan tahap efikasi kendiri guru adalah tinggi. Seterusnya, kajian yang dijalankan oleh Nurulakhma Yahya, Harun Baharudin dan Mohd Isa Hamzah (2017) juga mendapati bahawa tahap efikasi kendiri guru adalah tinggi dalam pengajaran bahasa Arab. Melihat kepada hasil dapatan kajian mereka ini, jelas menunjukkan bahawa efikasi kendiri guru dalam aspek strategi pengajaran, pengurusan bilik darjah dan penglibatan murid dalam pengajaran dan pembelajaran adalah tinggi. Selain itu, kajian luar negara oleh Azizuddin, Fleva dan Qazi (2015) juga mendapati tahap efikasi guru sekolah di India adalah tinggi. Kemudian, kajian oleh Linda Hoxha dan Zamira Hyseni-Duraku (2017), juga menunjukkan tahap efikasi kendiri guru adalah tinggi. Hasil kajian ini juga mendapati bahawa tanggapan individu dan rangsangan intelektual merupakan peramal yang kuat terhadap efikasi kendiri guru dalam pengajaran.

Kajian ini juga mendapati bahawa komitmen organisasi pendidikan dalam kalangan guru adalah berada pada tahap yang tinggi. Kajian ini secara selari dengan kajian lepas oleh Azizul dan Mohamed Yusoff (2018) yang mendapati tahap komitmen organisasi tinggi terhadap organisasi pendidikan. Kajian Nurharani et al. (2013) juga konsisten dengan kajian ini di mana mendapati komitmen organisasi 186 orang guru di sekolah menengah daerah Klang berada pada tahap yang tinggi. Kajian Najeemah (2012) ini turut menyamai dapatan mengenai komitmen organisasi guru terhadap organisasi di 5 buah sekolah rendah di Pulau Pinang. Hasil kajian tersebut mendapati komitmen organisasi guru terhadap sekolah adalah tinggi. Dapatan kajian ini juga selari dengan kajian yang dilakukan oleh Necmi Gokyer (2018), Zuraidah Muda dan Mohamed Yusoff Mohd Nor (2018) dan Mohd Khairuddin Abdullah et al. (2017). Dapatan melalui penyelidikan ini menunjukkan keselarian dengan dengan Teori Komitmen Meyer dan Allen (1984) di mana guru mempunyai komitmen yang kuat untuk terus kekal bersama sekolah dan berusaha untuk mencapai matlamat sekolah.

Kajian ini menyimpulkan bahawa hubungan antara pemboleh-pemboleh ubah bebas dengan pemboleh ubah bersandar adalah signifikan. Walau bagaimanapun, kekuatan hubungan adalah sederhana diperoleh antara kepimpinan teknologi pengetua dalam pengurusan kurikulum dengan efikasi kendiri guru. Secara keseluruhannya, darjah hubungan linear antara kepimpinan teknologi pengetua dalam pengurusan kurikulum dengan efikasi kendiri guru adalah positif. Efikasi kendiri guru juga penting dan mempunyai hubungannya dengan keberkesanan kepimpinan di sekolah dalam meningkatkan kualiti dan mutu sistem pengurusan di sekolah. Tinjauan terhadap penyelidikan Chee (2012) memberikan isyarat yang jelas bahawa kepimpinan teknologi pengetua mempunyai hubungan yang signifikan terhadap efikasi kendiri guru. Beliau menyatakan bahawa kepimpinan teknologi pengetua mempengaruhi penggunaan ICT oleh guru dalam pengajaran adalah secara langsung dan tidak langsung melalui efikasi kendiri guru bergantung kepada tahap kemahiran ICT guru. Dapatan ini juga sejajar dengan kajian terdahulu yang mempunyai penemuan yang sama seperti Linda Hoxha dan Zamira Hyseni-Duraku (2017).

Kajian ini juga mendapati komitmen organisasi pendidikan bertindak sebagai moderator penuh kepada hubungan antara kepimpinan teknologi pengetua dalam pengurusan kurikulum dengan efikasi kendiri guru. Memandangkan bahagian ini adalah jurang utama kajian ini, maka tidak terdapat kajian lepas yang sama dengan kajian ini. Sehubungan dengan itu, penyelidik tidak dapat membuat perbincangan dan perbandingan secara khusus terhadap dapatan kajian ini. Kajian-kajian lepas lebih tertumpu kepada hubungan langsung antara pembleh ubah-pemboleh ubah yang dikaji sebagaimana yang telah dibincang di bahagian lain di atas.

Namun begitu, jika dirujuk kepada kajian lain iaitu kajian yang menggunakan komitmen organisasi sebagai moderator tetapi bukan dalam pendidikan. Dapatan kajian ini selari dengan kajian oleh Ajimat (2019), Butali dan Njoroge (2017), Sabwami Butali (2015) dan Tan dan Lim (2012) di mana mendapati komitmen organisasi boleh memberi kesan yang signifikan terhadap perhubungan antara variabelvariabel yang dikaji. Di mana dengan adanya komitmen organisasi boleh meningkatkan prestasi dan pencapaian seseorang dan juga organisasi. 


\section{Implikasi dan Cadangan}

Secara rumusannya, hubungan antara pemboleh ubah bebas dengan pemboleh ubah bersandar adalah signifikan. Kekuatan hubungan adalah sederhana diperoleh antara pemboleh ubah kepimpinan teknologi dalam pengurusan kurikulum dengan efikasi kendiri guru. Secara keseluruhannya, darjah hubungan linear antara kepimpinan teknologi pengetua dalam pengurusan kurikulum dengan efikasi kendiri guru adalah positif. Kepimpinan pengetua amat penting bagi meningkatkan keberkesanan guru agar dapat mencapai kecemerlangan sekolah. Selain itu, kajian ini turut membuktikan bahawa komitmen organisasi pendidikan merupakan moderator penuh ke atas hubungan antara kepimpinan teknologi pengetua dalam pengurusan kurikulum dengan efikasi kendiri guru.

Penyelidikan ini memberi input terhadap beberapa teori yang mendasari kajian berkaitan efikasi kendiri guru dan kepimpinan teknologi pengetua dalam pengurusan kurikulum. Kajian ini membuktikan Teori Efikasi Kendiri Tschanen-Moran dan Hoy (2001) dan Model Efikasi Kendiri Guru Tschanen-Moran dan Hoy $(1998,2001)$ adalah menyokong dapatan kajian yang diperoleh. Kajian ini turut menyumbang terhadap kefahaman mengenai beberapa teori dan model berkaitan kepimpinan teknologi pengetua dalam pengurusan kurikulum seperti Teori Laluan Matlamat House (1971) dan Model Kepimpinan Leithwood dan Jantzi's (2006). Selain itu, kajian ini turut menyokong teori Teori Komitmen Meyer dan Allen (1984) dan Model Tiga Komponen Meyer dan Allen (1991) yang digunakan dalam kajian ini. Ringkasnya, kajian ini membuktikan bahawa teori dan model berkaitan masih relevan dengan situasi semasa.

Dapatan kajian ini membuka ruang dan menjadi panduan penyelidikan akan datang berkaitan peranan faktor komitmen organisasi pendidikan sebagai moderator terhadap hubungan antara kepimpinan teknologi pengetua dalam pengurusan kurikulum dengan efikasi kendiri guru. Hubungan antara kepimpinan teknologi pengetua dalam pengurusan kurikulum dan efikasi kendiri guru turut memberi maklumat tambahan berkaitan hubungan antara kedua-dua pemboleh ubah dalam kajian ini.

\section{Kesimpulan}

Berdasarkan penemuan kajian, didapati pemboleh ubah bebas iaitu kepimpinan teknologi pengetua dalam pengurusan kurikulum yang dikaji menunjukkan terdapat hubungan dengan efikasi kendiri guru. Komitmen organisasi pendidikan juga merupakan moderator terhadap hubungan antara kepimpinan teknologi pengetua dalam pengurusan dengan efikasi kendiri guru. Oleh itu, kepimpinan teknologi pengetua dalam pengurusan kurikulum perlu diamalkan dalam pengurusan di sekolah. Selain itu, komitmen organisasi pendidikan juga merupakan salah satu faktor penting dalam meningkatkan efikasi kendiri guru dan kecemerlangan sekolah. Keberkesanan pembaharuan dalam pendidikan bergantung kepada peranan yang dimainkan oleh pengetua dan guru, di samping pelbagai faktor selain aspek kepimpinan teknologi pengetua dalam pengurusan kurikulum seperti yang dirumuskan kajian ini.

\section{Rujukan}

Abdullah, N., Khalid, H., \& Hamzah, M. I. M. (2015). Amalan kepimpinan teknologi pengetua dalam pengintegrasian ICT di Sekolah Menengah Kebangsaan di Malaysia. Proceeding of the 3rd Global Summit on Education GSE 2015. Kuala Lumpur.

Abdulkareem, R., Chauhan, A., \& Maitama, K. (2015). The relationship between human resource management practices and employee's turnover intention among registered nurses in Nigerian public hospitals: The mediating role of organisational trust. UTM Press, 2, 95-98.

Ahmad, J., Ather, M. R., \& Hussain, M. (2014). Impact of Big Five personality traits on job performance (Organizational commitment as a mediator). Paper presented at the Management, Knowledge and Learning International Conference 2014, June 25-27, Portorož, Slovenia.

Akcil, U., Aksal, F. A., Mukhametzyanova, F. S., \& Gazi, Z. A. (2017). An examination of open and technology leadership in managerial practices of education system. EURASIA Journal of Mathematics, Science and Technology Education, 13(1), 119-131. 
Malaysian Journal of Social Sciences and Humanities (MJSSH), Volume 5, Issue 3, (page 30 - 46), 2020

DOI: https://doi.org/10.47405/mjssh.v5i3.373

Ali, S., Farid, F., \& Ibrarullah. (2016). Effect of Transformational Leadership on Job Satisfaction and Organizational Commitment. Humanistic Management Network, Research Paper Series No. $02 / 16$.

Alkrdem, M. (2014). Technological leadership behaviour of high school head teachers in Asia Region, Saudi Arabia. Journal of International Education Research (JIER), 10(2), 95-100.

Alt, D. (2018). Science teachers' conceptions of teaching and learning, ICT efficacy, ICT professional development and ICT practices enacted in their classrooms. Teaching and Teacher Education, 73, 141-150.

A. Maulod, S., Yan Piaw, C., Ahmad, H., Mei Wei, L., \& Alias, S. (2017). Kecerdasan Emosi Pengetua Dan Hubungannnya Dengan Efikasi Kendiri Guru Sekolah Menengah. JuPiDi: Jurnal Kepimpinan Pendidikan, 3(3), 54-75.

Ary, D., Jacobs, L. C., \& Razavieh, A. (1990). Introduction to research in education (4th ed.). Fort Worth, TX: Holt, Rinehart, and Winston.

Awanis Binti Mohd., Ainunmadiah Binti Mohd Nawawi., \& Siti Noor Binti Ismail. (2017). "Tahap Efikasi Guru Dan Hubungannya Dengan Pencapaian Sekolah Di Sekolah-Sekolah Menengah Dalam Daerah Bachok." Proceedings of the ICECRS 1, no. 1.

Azizuddin, K., Fleva, E., \& Qazi, T. (2015). Role of Self-Esteem and General Self-Efficacy in Teacherse Efficacy in Primary Schools. Psychology, 6,117-125.

Azizul Bin Asi \& Mohamed Yusoff Mohd Nor. (2018). Amalan Kepimpinan Distributif Guru Besar Dan Hubungannya Dengan Komitmen Organisasi Guru. Seminar Pendidikan Transdisiplin (Sted 2018).

Babbie, E. R. (2001). The Practice of Social Research $\left(9^{\text {th }}\right.$ ed $)$. Belmont, California: Wadsworth Thompson Learning.

Bandura, A. (1986). Social Foundations of thought and action: A Social Cognitive Theory. Prentice Hall, Englewood Cliffs.

Banoglu, K., Vanderlinde, R., \& Cetin, M. (2016). Investigation of principals' technology leadership profiles in the context of schools' Learning organization culture and ICT infrastructure: F@tih project schools vs the others. Education and Science, 41(188), 83-98.

Blum M. L., Naylor J. C. (1968). Industrial psychology. New York: Harper \& Row.

Butali, P. \& Njoroge, D. (2017). Training and Development and Organizational Performance: The Moderating Effect of Organizational Commitment. International Journal of Scientific Research and Management, 5(11), 7381-7390.

Cansoy, R., \& Parlar, H. (2018). Examining the relationship between school principals' instructional leadership behaviors, teacher self-efficacy, and collective teacher efficacy. International Journal of Educational Management, 32(4), 550-567.

Carlos, M. P., \& Filipe, C. (2011). From personal values to creativity: Evidence from frontline service employees. European Journal of Marketing, 45 (7/8), 1029-1050.

Chee K. S. (2012). The Influence of Principal's Technology Leadership on Teacher' Self- Efficacy and ICT Use In Teaching. (Doctoral Thesis). Universiti Malaysia Sarawak.

Chua, Y. P. (2006). Kaedah dan Statistik Penyelidikan Buku 1: Asas Statistik Penyelidikan. Kuala Lumpur: McGraw Hill.

Cocca, M., Cocca, A., Martinez, E. A., \& Bulnes, M. G. R. (2018). Correlation between self-efficacy perception and teaching performance: the case of Mexican Preschool and Primary School teachers. Arab World English Journal, 9(1), 56-70.

Cohen L., Manion L., \& Morrison K. (2007). Research Methods in Education. (6th Ed.) USA: Routledge.

Connor-Smith, J. K., \& Compas, B. E. (2002). Vulnerability to social stress: Coping as a mediator or moderator of sociotropy and symptoms of anxiety and depression. Cognitive Therapy and Research, 26(1), 39-55.

Dardas, L. A., \& Ahmad, M. M. (2015). Coping strategies as mediators and moderators between stress and quality of life among parents of children with autistic disorder. Stress and Health, 31(1), 512.

Esplin, N. L., Stewart, C., \& Thurston, T. N. (2018). Technology leadership perceptions of Utah elementary school principals. Journal of Research on Technology in Education, 0(0), 1-14.

Faridah Juraime, \& Mohd Izham Mohd Hamzah. (2017). Kepimpinan teknologi pengetua dan hubungannya dengan prestasi akademik sekolah di Malaysia. International Journal of Education, 
Malaysian Journal of Social Sciences and Humanities (MJSSH), Volume 5, Issue 3, (page 30 - 46), 2020

DOI: https://doi.org/10.47405/mjssh.v5i3.373

Psychology and Counseling, 2(5), 215-230. Retrieved from http://www.ijepc.com/PDF/IJEPC2017-05-09-17.pdf

Fisher, D. M., \& Waller, L. R. (2013). The 21st century principal: A study of technology leadership and technology integration in Texas K-12 schools. The Global E Learning Journal, 2(4), 1-44.

Fuziah, M. Y. \& Mohd Izham, M. H. (2011). A study of relationship between leadership practices and learning organization practices in cluster secondary schools. Jurnal Pendidikan dan Latihan MARA, 3(1), 41-56.

Gibson, S. \& Dembo, M. H. (1984). Teacher efficacy: a construct validation. Journal of Educational Psychology, 76 (4), 569-582.

Gokyer, N. (2018). Organizational Commitment of High School Teachers. Journal of Education and Training Studies, Vol. 6, No. 3a.

Hakimi Ismail. (2015). Cabaran Baharu Kerjaya Guru Abad Ke 21. Utusan Online. 15 Mei 2015.

Hatlevik, I. K. R., \& Hatlevik, O. E. (2018). Examining the relationship between teachers' ICT selfefficacy for educational purposes, collegial collaboration, lack of facilitation and the use of ICT in teaching practice. Frontiers in Psychology, 9(June), 1-8.

Hong, K. \& Koh, C. (2002). Computer anxiety and attitudes towards computer among rural secondary school teachers: A Malaysian perspective. Journal of Research on Technology in Education, 35 (1), 27-46.

Horton, T. (2013). The relationship between teachers' sense of efficacy and perceptions of principal instructional leadership behaviors in high poverty schools. (Unpublished Doctoral Tesis). University of Texas at Arlington.

Hoxha, L. \& Hyseni Duraku, Z. (2017). The Relationship between Educational Leadership and Teachers' Self-efficacy. The European Journal of Social and Behavioural Sciences EJSBS Volume XX (eISSN: 2301-2218).

Ibukun, W. O., Oyewole, B. K., \& Abe, T. O. (2011). Personality characteristics and principal leadership effectiveness in Ekiti state of Nigeria. International Journal of Leadership Studies, $6(2), 247-62$.

International Society for Technology in Education. (2009). National Education Technology Standards forAdministrators. Dipetik dari http://www.iste.org/docs/pdfs/nets-astandards.pdf. Pada 13 Mei 2019.

Jabatan Pendidikan Negeri Sabah. (2019). Data Bilangan Guru Mengikut Sekolah Dan PPD di Negeri Sabah. Kota Kinabalu: Sektor Pengurusan Maklumat dan ICT.

Joo, Y. J., Park, S., \& Lim, E. (2018). Factors influencing preservice teachers' intention to use technology: TPACK, teacher self-efficacy, and Technology Acceptance Model. Educational Technology and Society, 21(3), 48-59.

Kementerian Pendidikan Malaysia (KPM). (2013). Pelan Induk Pembangunan Pendidikan Malaysia 2013-2025. KPM: Putrajaya.

Khair Mohamad Yusof. (2015). “Guru: Membina Ilmu Menyempurnakan Akhlak”. Teks Ucapan Perutusan Hati Guru 2015, Ketua Pengarah Pelajaran sempena Perayaan Hari Guru ke-44.-15 Mei 2015.

Khairiah, H. (2013). Kepemimpinan instruksional pengetua, birokrasi sekolah dan efikasi kendiri guru di sebuah MRSM di Melaka. (Dissertasi Sarjana Kepengetuaan) Universiti Malaya, Kuala Lumpur.

Korman A. K. (1974). Contingency approaches to leadership: An overview. In Hunt J. G. Larson L. L. (Eds.), Contingency approaches to leadership (pp. 189-195). Carbondale, IL: Southern Illinois University Press.

Krejcie, R. V and Morgan, D. W. (1970). Determining Sample Size for Research Activities. Educational and Psychological Measurement, 30: 607-610.

Leithwood, K., \& Jantzi, D. (2006). Transformational School Leadership for Large-Scale Reform: Effects on Students, Teachers, and Their Classroom Practices. School Effectiveness and School Improvement, 17(2), 201-227.

Leong, M. W. (2017). Principal Technology Leadership Practices, Teacher Ict Competency, And Teacher Acceptance Of School Management System (SMS) In Negeri Sembilan Secondary Schools. (Doctoral Thesis), University of Malaya, Kuala Lumpur. 
Malaysian Journal of Social Sciences and Humanities (MJSSH), Volume 5, Issue 3, (page 30 - 46), 2020

DOI: https://doi.org/10.47405/mjssh.v5i3.373

Levin, R. I., \& Rubin, D. S. (1998). Statistics for Management in Classroom. New York: Holt, Rinehart and Wilson.

Littleton, H., Horsley, S., John, S., \& Nelson, D. (2007). Trauma coping strategies and psychological distress: A meta-analysis. Journal of Traumatic Stress, 20(6), 977-988.

Madiha, S. (2012). the impact of teachers' collegiality on their organizational commitment in high-and low-achieving secondary schools in Islamabad, Pakistan. Journal of Studies in Education. 2(2), 130-156.

Mansor, R., \& Hamzah, M. I. M. (2015). Kepimpinan Berkualiti: Perspektif mengenai kompetensi yang diperlukan untuk Memimpin dengan Berkesan. Jurnal Pengurusan, 45, 143-154.

Mareena, M., Norhasni, Z. A., Ismi, A. I., \& Azizan, A. (2011). Tinjauan hubungan gaya kepimpinan dengan komitmen organisasi. Eksplanasi, 6(1), 17-28. Retrieved from http://merr.utm.my/id/eprint/4862

Mathew, G. A. \& Zacharias, S. D. (2016). A Conceptual Overview on Relationship between Employee Attitude towards Training and Organizational Commitment. In Proceedings of International HR Conference (Vol. 3, No. 1).

Metcalf, W. B. (2012). K-12 principals' perceptions of their technology leadership preparedness (Unpublished doctoral dissertation), Georgia Southern University. Dipetik dari https://digitalcommons.georgiasouthern.edu/cgi/viewcontent.cgi?article=1400\&context=etd. Pada 4 April 2019.

Mei Kin, T., Abdull Kareem, O., Nordin, M. S., \& Wai Bing, K. (2018). Principal change leadership competencies and teacher attitudes toward change: the mediating effects of teacher change beliefs. International Journal of Leadership in Education, 21(4), 427-446.

Mohd Izham Mohd Hamzah, Faridah Juraime, Aida Hanim A. Hamid, Norazah Nordin \& Noraini Attan. (2014). Technology leadership and its relationship with School-Malaysia Standard of Education Quality (School-MSEQ). International Education Studies, 7(13), 278-285.

Mohd Khairuddin, A., Maspiah, S., \& Halimah, L. (2017). Kecerdasan Emosi dan Komitmen Guru Terhadap Organisasi. Jurnal Psikologi dan Kesihatan Sosial (JPsiKS), 1, 44-54.

Mohd Majid, K. (2000). “Kaedah Penyelidikan Pendidikan”. Kuala Lumpur: Dewan Bahasa dan Pustaka.

Mohammed Sani, I., Ghavifekr, S., Ling, S.M.L., Siraj, S. \& Azeez, M. I. K. (2014). Can transformational leadership influence on teachers' commitment towards organization, teaching profession, and students learning? A quantitative analysis. Asia Pacific Education Review, 15(2), 177-190.

Mohd Yusof Abdullah. (2006). Pengaruh Motif, Sikap dan Latihan Perguruan Terhadap Profesionalisme Keguruan di Kalangan Pelajar Program Pendidikan IPTA. Tesis Doktor Falsafah. Universiti Malaysia Sabah, Kota Kinabalu, Sabah.

Moktar Johar. (2011). Kepimpinan teknologi dan kompetensi ICT guru di SM Agama di Daerah Kuching Sarawak. Tesis Sarjana Kepengetuaan. Institut Kepengetuaan, Universiti Malaya.

Najeemah, M. Y. (2012). School climate and teachers' commitment: A case study of Malaysia. International Journal of Economics Business and Management Studies, 1(2), 65-75. Dipetik dari https://ssrn.com/abstract=2151470. Pada 5 Julai 2019.

Norhayati, M. D., \& Aida Hanim, A. H. (2018). Kepimpinan Teknologi Pengetua dan Hubungan Terhadap Kompetensi ICT Guru Sekolah Menengah Kebangsaan Daerah Seremban dan Kuala Pilah. Prosiding Seminar Kebangsaan Majlis Dekan Pendidikan Universiti Awam 2018. Dipetik dari http://www.unisza.edu.my/medc2018. Pada 12 Mac 2019.

Noor Zailani, K., \& Azlin Norhaini, M. (2017). Kompetensi Guru Besar Dan Efikasi Kendiri Guru Sekolah Rendah Di Daerah Padang Terap Kedah. Prosiding Pendidikan Serantau ke-VIII (2017). Fakulti Pendidikan, UKM.

Nurharani, S., Norshidah, N., \& Afni Anida, A. (2013). Rekindle teacher's organizational commitment: The effect of transformational leadership behavior. Procedia - Social and Behavioral Sciences, 90, 566-574.

Nurulakhma, Y., Harun, B., \& Hamzah, M. I, M. (2017). Efikasi Kendiri Guru Dalam Pengajaran Bahasa Arab. Malaysian Online Journal of Education. Fakulti Pendidikan, Universiti Kebangsaan Malaysia.

Ozkan, T., Tokel, A., Celik, M., \& Oznacar, B. (2017). Evaluation of technology leadership in the context of vocational school administrators. In Proceedings of the 9th International Conference 
Malaysian Journal of Social Sciences and Humanities (MJSSH), Volume 5, Issue 3, (page 30 - 46), 2020

DOI: https://doi.org/10.47405/mjssh.v5i3.373

on Computer Supported Education (Vol. 1, pp. 727-731). SCITEPRESS - Science and Technology Publications.

Pelan Pembangunan Pendidikan Malaysia (PPPM: 2013- 2025). (2012). Kementerian Pendidikan Malaysia. Dipetik dari http://www.moe.gov.my/v/pelan-pembangunan-pendidikan-malaysia2013-2025. Pada 26 Mei 2019.

Rabindarang, S., Khuan, W. B., \& Khoo, Y. Y. (2014). Educators' reflection on organizational commitment in technical and vocational education. International Journal of Scientific and Research Publications, 4(2).

Rabindarang, S., Khuan, W.B., \& Khoo, Y. Y. (2018). Amalan Kepimpinan Distributif terhadap Komitmen Organisasi Dalam Pendidikan Teknik dan Vokasional. International Journal of Education and Training (InjET) 4(2) November: 1-9 (2018).

Razak, N. A., Darmawan, I. G. N., \& Keeves, J. P. (2010). The influence of culture on teacher commitment. Social Psychology of Education, 13(2), 185-205.

Sabwami, P. B. (2015). Organizational Commitment As a Moderator of the Relationship Between High Performance Work practices and Organizational Performance. The Strategic Journal of Business \& Change Management, 2(7), 108-133.

Saimah binti Kiwal. (2013). Hubungan di antara komitmen dan tahap kepuasan kerja guru dalam meningkatkan prestasi pencapaian akademik murid sekolah rendah kebangsaan Kawasan pedalaman Daerah Kota Marudu. Tesis. Universiti Malaysia Sabah.

Sathiamoorthy, K. (2013). Kepimpinan teknologi pengetua. Kolokium ICT dalam pengurusan dan kepimpinan pendidikan 2013. Institut Aminuddin Baki.

Shafinaz A Maulod, Chua, Y. P., Hussein, A, Leong, M. W., \& Shahrin, A. (2016). Kecerdasan emosi pengetua dan hubungannya dengan efikasi kendiri guru sekolah menengah. Jurnal Kepimpinan Pendidikan, 3(3), 54-75.

Shafinaz, A. Maulod. (2017). Hubungan antara kecerdasan emosi dan kepimpinan instruksional pengetua dengan efikasi kendiri guru sekolah menengah kebangsaan di Negeri Sembilan/Shafinaz A. Maulod (Doctoral dissertation, University of Malaya).

Sun, A., \& Xia, J. (2018). Teacher-perceived distributed leadership, teacher self-efficacy and job satisfaction: A multilevel SEM approach using the 2013 TALIS data. International Journal of Educational Research, 92, 86-97.

Tan, T. H. \& Lim, Y. K. (2012). Organizational commitment as a moderator of the effect of training on service performance: An empirical study of small to medium-sized enterprises in Malaysia. International Journal of Management, 29(1), 65-76.

Terborg J. R. (1980). Why must we spell interaction with an "X": Some alternative views of person X situation interactions. Paper presented at the meeting of the Southwest Academy of Management San Antonio.

Thannimalai, Raamani and Raman, Arumugam (2018). The Influence of Principals' Technology Leadership and Professional Development on Teachers' Technology Integration in Secondary Schools. Malaysian Journal of Learning and Instruction (MJLI), 15(1), 201-226.

Toprak, M. \& Summak, M. S. (2014). Involvement in Change and Commitment to Change: A Study at Public Schools. International Journal of Social Sciences \& Education, 4(4), 953-968.

Tschannen-Moran, M., Hoy, A. W., and Hoy, W. k. (1998). Teacher efficacy: Its meaning and measure. Review of Educational Research, 68: 202-248.

Tschannen-Moran, M and Hoy, A. W (2001). Teacher Efficacy: Capturing an elusive construct. Teaching and Teacher Education, 17: 783-805.

Ugur, N. G., \& Koc, T. (2019). Leading and teaching with technology: School principals' perspective. International Journal of Educational Leadership and Management, 7(1), 42.

Utusan Borneo Sabah. (2017). Kualiti Pengajaran Guru: Isu dan Cabaran Semasa. Dipetik dari https;//www.pressreader.com/Malaysia/utusan-borneo-sabah/20170419/282643212426811. Pada 16 Oktober 2019.

Wong, A. Y., \& Khadijah Daud. (2017). Technology leadership in Malaysia's High Performance School. Journal of Education and E-Learning Research, 4(1), 8-14.

Yukl G. A. (2010). Leadership in Organization (7th Ed). Upper Saddle River, NJ: Prentice Hall.

Yukl, G. (2013). Leadership in Organizations (8th Ed). New Jersey: Pearson Education, Inc.

Zedeck S. (1971). Problems with the use of "moderator" variables. Psychological Billetin, 76, 295310. 
Malaysian Journal of Social Sciences and Humanities (MJSSH), Volume 5, Issue 3, (page 30 - 46), 2020

DOI: https://doi.org/10.47405/mjssh.v5i3.373

Zuraidah M. \& Nor, M. Y. M. (2018). Modal Psikologi Dan Komitmen Guru Dalam Organisasi Pendidikan. Seminar Antarabangsa Isu-Isu Pendidikan (ISPEN2018). Fakulti Pendidikan, Universiti Malaya. 